\title{
Scientometric analysis of the activities of the International Commission for Continental Erosion (ICCE)
}

\author{
Valeriy P. Bondarev ${ }^{1,2}$ \\ ${ }^{1}$ Faculty of Geography, Lomonosov Moscow State University, Moscow, 119 991, Russia \\ ${ }^{2}$ Faculty of Social Sciences and Humanities, Bauman Moscow State Technical University, \\ Moscow, 105 005, Russia \\ Correspondence: Valeriy P. Bondarev (valery_bondarev@mail.ru) \\ Published: 1 August 2019
}

\begin{abstract}
The article is dedicated to the analysis of the International Commission of Continental Erosion (ICCE) of International Association of Hydrological Sciences (IAHS) activity since foundation in 1981. The empirical data is the collections of scientific articles, published in IAHS Red Books after symposiums and workshops, organized by the ICCE. 2460 authors published articles in Red Books, $81 \%$ of them have publication in the one issue. The most active contributors (who have articles in 7 or more issues) compose a group of 39 scientists (1.6\% from the total number of authors). Researchers from 89 countries were published articles in the ICCE issues of Red Books. The activity of the ICCE can be described by a cyclic model of growth. It is shown that the ICCE scientific community is becoming progressively global.
\end{abstract}

\section{Introduction}

In a broad sense a scientific community is understood as a complex self-organizing system, which includes along with individual scientists, also various state institutions, public and commercial organizations, formal and informal groups, etc., which are interacting in the process of scientific activity both with one another and with external environment. The study of structure and functioning of scientific groups and communities is required to determine their role in the development of a certain scientific direction, to forecast the main trends of such development, and to increase the efficiency of management in scientific activities.

Traditionally the research subject in the area of scientific communities is a scientific laboratory, which is recognized to be the most important unit of collective scientific activity. There is abundant proof of studying a scientific laboratory as the main structure element of a scientific community (Pelz and Andrews, 1966; Knorr-Cetina, 1981, 1999; Woolgar and Latour, 1986). Typically, only sustainable and productive scientific groups can be taken as a research subject, since their history allows to trace the dynamics of their development during long-term time interval. The scientometric analysis of Makkaveev Scientific Laboratory of Soil Ero- sion and Channel Processes of Geographical Faculty of the Moscow State University can be shown as an example of such analysis (Bondarev and Boichenko, 2010, 2011). The described methodology of research can be used as a proven basis for further investigation of scientific groups and communities.

One of the least studied types of scientific communities are relatively stable international or interregional research groups that are created and operate in the process of interaction within regular conferences and meetings. As a rule, such conferences and meetings are organized by a small group of activists (both individuals and organizations), whose main purpose is to coordinate segmental research in a specific scientific area. The Interuniversity Scientific Coordination Council on the Problem of Erosion, Channel and Estuarial Processes at Lomonosov Moscow State University is an example of such scientific community (Bondarev and Rulyova, 2018).

The ICCE is another example of a sustainable and productive super-institutional scientific community. The goal of this study is to define basic scientometric characteristics of the ICCE functioning since the period of foundation in 1981. 


\section{Object of study}

According to the information from the official website (International Commission on Continental Erosion, 2019) it is one of the Commissions of the International Association of Hydrological Sciences (IAHS). The ICCE fields of interests include the erosion, transport and deposition of sediment and associated nutrients and contaminants and the interaction of these processes with other components of the hydrological cycle and the environment. ICCE underlines the fundamental role of erosion and sediment delivery in many environmental issues, and supports the inter-disciplinary researches aimed to improve our understanding and management of such issues.

There are eight ICCE officers, who take the most active participation in supporting of the Commission activity. Since 1981 ICCE organize Symposia and workshops. The all oral and in some cases poster presentations were published in 37 IAHS "Red Books" and a few special issues of the International Journals, edited by members of ICCE group (ICCE Publications, 2019). These publications were taken as the main data set for the scientometric analysis.

\section{Methods of study}

Investigation of communicative interactions within scientific communities is the most important tool of scientometric analysis (Blinnikov, 1976; Woolgar and Latour, 1986; Ogurtsov, 2011). Latour and Woolgar (1986) were the first who proposed to identify of scientific groups by means of a special analysis of scientific communications. Professional scientific activity provides for extensive contacts, because process of scientific research presume that the scientist is in contact with many communication parties, each of which has its certain role in the process of accumulation and distribution of scientific knowledge. Therefore, it is impossible to assess the current condition and prospects for the development of a certain scientific group without the study of its communicative interactions.

Publication activity is commonly believed to be the most informative criteria for studying and evaluating a scientific group. Generally, the publication activity is understood as a statistical analysis of a designated publication array, selected to comply with the current research issues. The importance and applicability of this kind of research is based on the definition of scientific publication as the final result of both individual and collective scientific activities. The statistical analysis of publication array allows to make conclusions about: (a) the principals of labour specialization in science, based on the study of co-author relations; (b) the correlations in cross-disciplinary fields of study, based on thematic analysis; (c) the productivity of scientific group, based on the quantity and volume of publications, etc. (Dumenton, 1987). Thus, the publication array forms a specific data field of the partic-

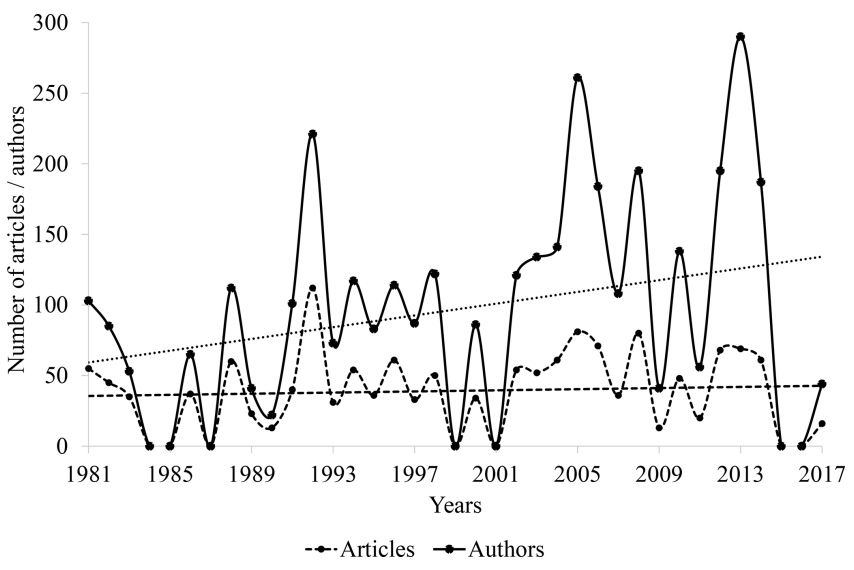

Figure 1. Dynamics of the number of participants in ICCE events: (a) - number of reports presented at the events; (b) - number of researchers who submitted as participants to the event.

ular scientific community, and may serve as the main subject for its scientometric analysis.

\section{Publication activity of the ICCE group members}

ICCE arranges symposia and workshops on regular basis. The proceedings of the scientific meetings are published in IAHS "Red Books" and Special Issues of International Journals (for the purposes of the current study both types of publications will be hereafter named "the issues"). During the years of activity, IAHS Press has published 35 issues related to ICCE organized Symposia and workshops. To identify the common activity of ICCE members, the number of articles, article co-authors and countries, which they represented, have been counted for each issue. The individual issue for the time window 1981-2017 at an average included 39 articles written by 97 authors from 20 countries. The time fluctuations in the publication activity is presented on Fig. 1. It is possible to identify the two trends. Firstly, the general increase of the number of article co-authors This trend might result from the fact that nowadays scientific activity in the Earth Sciences become more collective due to increasing of number of methods and techniques, which are using for receiving final results Secondly, cyclic variability of number of articles in the issues. This trend can be explained the differences in the topics discussed during Symposia or workshop.

It is worth mentioning that during the whole period of ICCE activity, the most frequent number of co-authors is two. $88 \%$ of the articles have from 1 to 4 authors. And while at the beginning of ICCE activity the tendency was more for one author per article, over recent years it is more typical, that number of co-authors are three per article (Fig. 2).

The activity of single authors and participating countries were also examined. There are several criterias in scientometrics, which allow to determine leaders in scientific communities. One of them is based on the well-known Pareto 


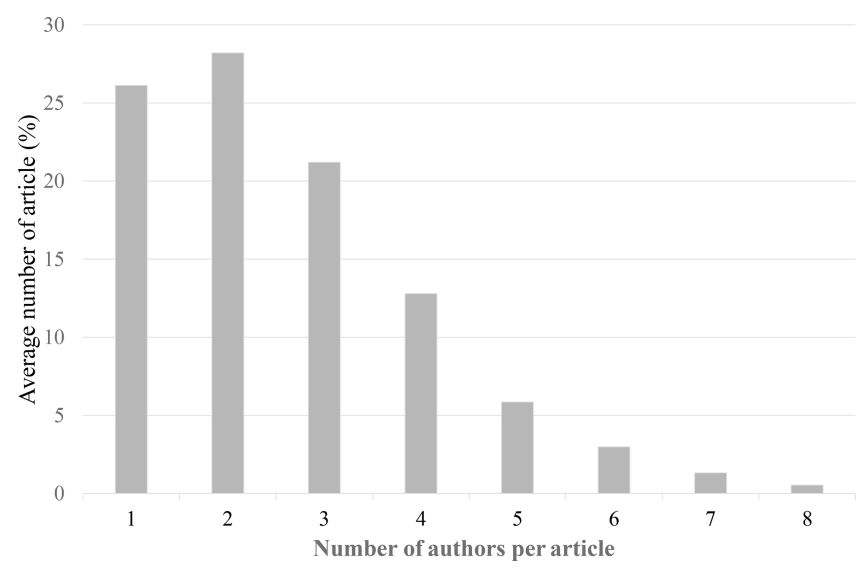

Figure 2. Average number of authors per article between 1981 and 2017.

principle, which states that, for many events, $80 \%$ of the effects come from $20 \%$ of the causes. The Pareto principle has a bearing on the most general trends and is widely used in economy and sociology. The statistical analysis of 37 issues allows us to reveal ICCE leaders among its regular members. The statistical analysis of 37 issues allows us to reveal ICCE leaders among its regular members. The total number of coauthors are 2460 scientists in total, $81 \%$ from them (2000 authors) were co-author of publication in just one issue, whilst $19 \%$ (460 co-authors) have had published articles in two or more issues. The most active scientists (who have participated in 7 or more issues) compose a group of 39 members or less than $1.6 \%$ from the total number of authors.

As for the geography of participation, articles written by researchers from 89 countries were published in the ICCE issues during the examined time window 1981-2017. The absolute leaders in the number of co-authors are the UK, Germany, the USA, Canada and China (with Hong Kong). The scientists from the following countries are quite active in the participation and preparation of articles in the ICCE issues: Australia, France, India, Russia, Italy, Poland, Japan, Brazil, The Netherlands, Spain, Denmark, and Norway. There are 28 countries, which representatives took part in the preparation of articles for 8 or more issues of ICCE Proceedings (either IAHS Red Books or Special Issues of International Journals).

To analyze the structure of research teams the following data were examined: the number of articles with a single author, with co-authors from one organization, with co-authors from one country, with co-authors from different countries (Fig. 3). Unfortunately, data row ends in 2014, as the subsequent materials do not contain information concerning country of the article authors. It is possible to note the permanent reduction of the number of single authors. The number of co-authors from one organization remains quite stable, but the numbers of co-authors from different organizations and different countries are constantly increasing. The emerging and steady growth of the number of international teams wit-

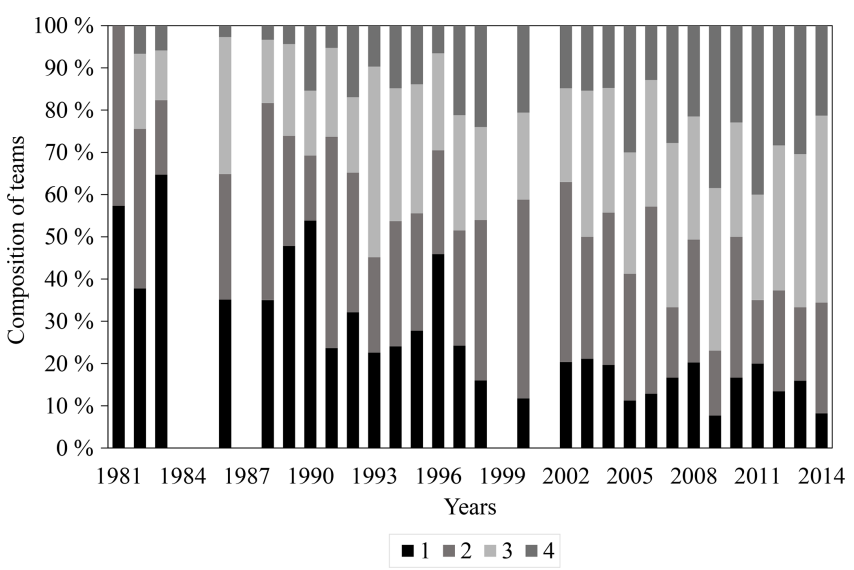

Figure 3. Time changes in the ratio of articles prepared with the participation of a different set of co-authors and published in ICCE edited issues. Legend: Articles prepared by: 1 - individual authors; 2 - co-authors from one organization; 3 - co-authors from one country (national team); 4 - international team.

nesses that the process of globalization which influences all spheres of the society, has a distinctive impact on the structure of modern scientific groups. Inter alia the ICCE scientific community is becoming progressively global.

\section{Conclusions}

Scientometric analysis of the ICCE activity shows, that the ICCE scientific community has been actively developing to become at the moment "formed" and "stable" and to evidently have a strong potential for further growth. The statistics analysis of publication array allows to reveal a wide geography of its members, a significant number of participants, and an active core of high-profile scientists which allows this community to organize Symposia and workshops on the regular way. The analysis internal and external contacts, structure of research teams allows to conclude that the ICCE organizational framework and functioning are stable and adaptive enough to give this scientific community hopeful prospects for a sustainable future. The results of study can be useful both for the ICCE management and for its active participants, since they include original data revealing some special aspects of the ICCE structure and functioning as a super-institutional scientific community. Besides, the research data might be of interest to some specialists in the field of scientometrics and sociology of science.

Data availability. Data is available at https://doi.org/10.5281/zenodo.3262389 (Bondarev, 2019).

Competing interests. The author declares that there is no conflict of interest. 
Special issue statement. This article is part of the special issue "Land use and climate change impacts on erosion and sediment transport". It is a result of the ICCE Symposium 2018 - Climate Change Impacts on Sediment Dynamics: Measurement, Modelling and Management, Moscow, Russia, 27-31 August 2018.

Acknowledgements. Processing of empirical data was carried out according to the plan of Research Laboratory of Soil Erosion and Channel Processes Lomonosov (Moscow State University), theoretical interpretation was carried out according to the research plan of Department of Sociology and Cultural Studies (Bauman Moscow State Technical University). The author is grateful to the following persons for their contribution: Valentin Golosov for his helpful advice and explanations of specific features of the ICCE structure and functioning, Olga Boichenko and Julia Yakubova for the assistance in text processing.

\section{References}

Bondarev, V.: Basic scientometric characteristics of ICCE, Zenodo, https://doi.org/10.5281/zenodo.3262389, 2019.

Bondarev, V. and Boichenko, O.: Structure and Dynamics of scientific Lab staff, Sotsiologicheskie Issledovanya [Sociological Studies], 11, 52-63, 2010 (in Russian).

Bondarev, V. and Boichenko, O.: The structure and functioning of the research team (communicative aspect), MSU Vestnik, 18, Sociology and Political Science, 1, 80-97, 2011 (in Russian).
Bondarev, V. and Rulyova, S.: Structure and Dynamics of Meta-Organizational Scientific Communities, Sotsiologicheskie Issledovanya [Sociological Studies], 5, 32-144, https://doi.org/10.7868/S0132162518050124, 2018 (in Russian).

Blinnikov, L. V. (Ed.): Communication in modern science, Moscow, Nauka, 1976 (in Russian).

Dumenton, G. G.: The Network of scientific communication and organization of fundamental research, Moscow, Nauka, 366 pp., 1987 (in Russian).

ICCE Publications: International Commission on Continental Erosion, available at: http://www.icce.altervista.org/ icce-publications.html/, last access: 15 May 2019.

International Commission on Continental Erosion: available at: http://www.icce.altervista.org/, last access: 15 May 2019.

Knorr-Cetina, K.: The manufacture of knowledge: an essay on the constructivist and contextual nature of science, Oxford, New York, Pergamon Press, 204 pp., 1981.

Knorr-Cetina, K.: Epistemic cultures: how the sciences make knowledge, Cambridge, Massachusetts, Harvard University Press, 352 pp., 1999.

Ogurtsov, A. P.: Scientific discourse: power and communication (complementarity of the two traditions), Philosophy of science: the twentieth century, St. Petersburg, 2, 12-59, 2011 (in Russian).

Pelz, D. C. and Andrews F. M.: Scientists in Organizations: Productive Climates for Research and Development, Oxford, England, John Wiley, 393 pp., 1966.

Woolgar, S. and Latour, B.: Laboratory life: the construction of scientific facts, Princeton, New Jersey, Princeton University Press, 296 pp., 1986. 